\title{
Mitral Valve Prolapse - A Case Study
}

\section{Pallavi $^{1 *}$ and K Suresh ${ }^{2}$}

${ }^{1}$ Nursing, MPH Scholar Karnataka State Rural Development and Panchayat Raj University (KSRDPRU), India

${ }^{2}$ Public Health Consultant and Visiting Professor, MPH, KSRDPRU Gadag, Bengaluru, Karnataka, India

*Corresponding Author: Pallavi, Nursing, MPH Scholar Karnataka State Rural Development and Panchayat Raj University (KSRDPRU), India.
Received: April 14, 2021

Published: April 26, 2021

(C) All rights are reserved by Pallavi and $\mathbf{K}$ Suresh.

\begin{abstract}
A 25-year nursing graduate Lady with H/o of chest discomfort, palpitations, fatigue, dizziness, shortness of breath consults a cardiologist. The cardiologist on physical examination records finds tachycardia (Pulse rate - 125/minute) but no other signs. Her 2 D Echocardiogram showed Ejection Fraction (EF) of $66 \%$ and she was diagnosed as having Mitral Valve prolapse (MVP) in the first week of February 2021. She was put on oral medication Metoprolol succinate $12.5 \mathrm{mg}$ for one month and advised for regular check up for every year or whenever required any symptoms recurred. Follow-up for 3 days indicated her to be normal and continues to be doing well. She is advised an annual health check-up, regular sleep, stress free living and maintaining healthy lifestyle through yoga, physical exercises, and meditation.
\end{abstract}

Keywords: Mitral Valve Prolapse; Haemoglobin; Tricuspid

\section{Background}

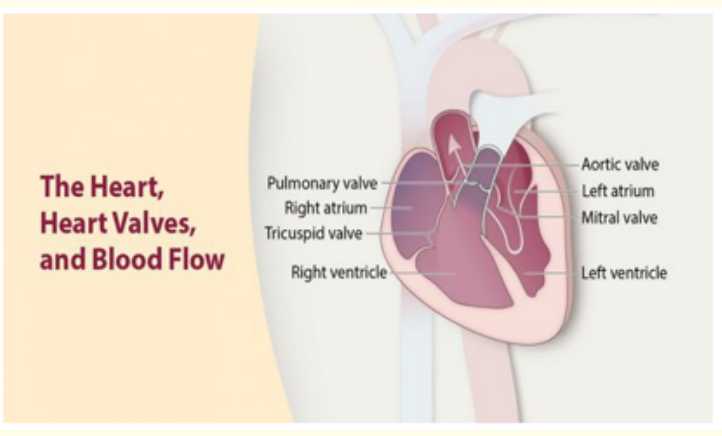

Figure 1

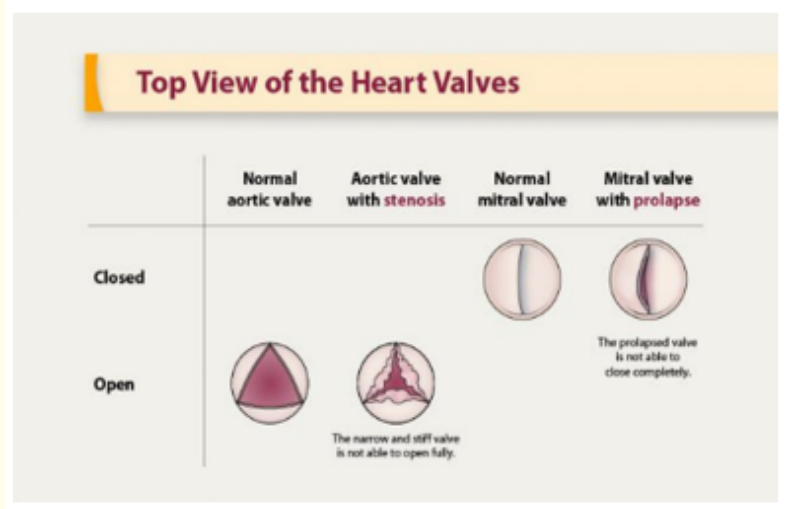

Figure 2 
Whenever anyone of the 4 valves in our heart gets damaged or diseased, we call it Valvular heart disease. A normal heart's anatomy consists of four chambers called right and left atria, and right and left ventricles and four valves namely Mitral, Tricuspid, Aortic and Pulmonary Valves. The main task of these valves is to control the blood flow from one chamber to another or the main blood vessels opening or closing to regulate the blood flow into the heart or away from the heart as indicate below:

- The mitral valve controls the blood flow from the left atrium to the left ventricle.

- $\quad$ The tricuspid valve controls blood flow from the right atrium to the right ventricle.

- The aortic valve facilitates blood flow from the left ventricle to the aorta.

- $\quad$ The pulmonary valve controls the blood flow from the right ventricle to pulmonary artery.

While the mitral valve has only two leaflets, the other three valves are composed of three leaflets or flaps that work together to open and close to regulate the blood to flow across the opening. (Figure 2). Diseased valves are unable fully open and close during each heartbeat, as do a healthy heart's valve leaflets. The aortic valve is most affected (60\%), though any valve in the heart can be diseased.

If the Diseased valves become "leaky" where they do not completely close; is called regurgitation. This results in the blood leaking back into the chamber that it came from and not enough blood can be pushed forward through the heart for proper physiological functioning. Mitral valve disease is the second in order (15\%), all other valves forming the third group. The other common problem called valvular stenosis happens when the valve is narrowed and stiff and unable to open fully to allow the blood pass through easily (Figure 2) [1].

\section{Introduction}

Mitral Valve Prolapse (MVP) is a type of myxomatous disease when the tissue of the valve leaflets and Chordae Tendinae are abnormally stretchy. Because of flabbiness whenever the heart beats, the mitral valve blows or flops back into the left atrium. The condition manifests in variety of severity from just a mild leak to a very floppy, leaky valve. Most cases of MVP have no or a mild leak and therefore does not become a cause for concern. But only a small percentage of cases may require further treatment. Global reports indicate that Mitral valves prolapse affects about $3-5 \%$ of the population and in females it is double of that in males. Mitral Valve Prolapse (MVP) is one of the most prevalent cardiac valvular abnormalities, occurring in almost $2-3 \%$ of the Indian population and affects Children, teens and adults alike. It is the commonest predisposing cause of infective endocarditis.

\section{Case Presentation}

A 25-year-old Nursing graduate studying MPH consulted a cardiologist with $\mathrm{H} / \mathrm{o}$ chest discomfort, palpitations, fatigue, dizziness, shortness of breath and Anxiety just before the semester examination. She had similar history of similar attacks for 4 years. On examination her Temperature - 97 F, Blood Pressure - 110/70 mmhg, Pulse rate - 125/minute, RR - 16/minute and no other cardiac failure signs like pedal or facial Oedema.

\section{Laboratory investigations}

Haemoglobin - $12.5 \mathrm{gm} / \mathrm{dl}$, Blood group - A positive, 2 D echocardiogram showed Ejection fraction (EF) of 66\%, Aorta - 3.2, Left atrium - 3.8, IVSd - 1.1, LVIDd- 40, LVPWd - 1.0 LVIDs - 2.5.

\section{Treatment}

She was diagnosed as a case of Mild Mitral Valve Prolapse (MVP) and put on Metoprolol succinate $12.5 \mathrm{mg}$ for one month and advised for regular check-up for every year or when required any symptoms repeated. She was advised for stress-free living, healthy lifestyle of doing regular exercise, yoga, and meditations.

\section{Follow-up}

The symptoms reduced within 3 days and there was no relapse, and the lady is doing fine for the last 2 months.

\section{Discussion}

Epidemiology

A systolic billowing of one or both mitral leaflets into the left atrium during ventricular systole (valve prolapse of $2 \mathrm{~mm}$ or more above the mitral annulus) is known as Mitral valve prolapse (MVP). It is the second most common cardiac valvular anomaly in developed countries. Myxomatous degeneration is the main aetiology of prolapsing valvar leaflets, explaining its rare occurrence before adolescence as evidenced by the Framingham study that indicated the prevalence of MVP was $2.4 \%$ of adult subjects in comparison with the prevalence of $0.7 \%$ in a population of healthy teenagers. 


\section{Pathology}

MVP is a clinical entity with or without thickening of mitral valve leaf's $5 \mathrm{~mm}$ or greater during diastasis. There may be mitral regurgitation or not. Primary MVP may have familial history or not. As both the rough and clear zones of leaflets are involved, there will be inter-chordal hooding due to leaflet redundancy. Marked proliferation of the spongiosa that causes focal interruption of the fibrosa is the main microscopic feature of primary prolapse. Subsequently fibrosis of the surface of the mitral value leaflets, thinning or elongation of the Chordae Tendinae and ventricular friction lesions may occur.

\section{Genetics}

Several chromosomal loci have been identified to infer that familial MVP is transmitted as on autosomal trait. Marfen syndrome and other connective tissue diseases (hlers-nanlos syndrome, osteo-genesis imperfecta, and dominant cutis laxa or pseudoxanthoma elasticum) patients reported to behaving higher incidence of Primary MVP

\section{Indications for surgery}

When in some patients there is a gradual progression of mitral regurgitation, or spontaneous rupture of Mitral Valve chordae tendinea or their marked elongation occurs, patients will develop a flail mitral leaflet. As the mortality rate in patients with severe MR caused by flail leaflets is $6 \%$ to $7 \%$ per year surgery is indicated. In a study using two-dimensional echocardiography prospectively surveyed 213 healthy urban school children between 3 and 12 years of age [2] and indicated that the prevalence of mitral valve prolapse (MVP) was age related as 28 of 213 (13.1\%) children had MVP [2].

A population-based study was conducted by Pang-yen-Liu., et al. (2021) study showed that 28 participants (3.3\%) had MVP, which was more prevalent in males. Participant with MVP had lower level of Body mass Index and fasting plasma glucose and had a higher prevalence of Intolerable somatic symptoms including chest pain, Dyspnoea, or easy Palpitation during Exercise than those without MVP [3].

A systematic review and Meta-analysis by Hui-Chen Han., et al. (2018) showed that 79 articles describing 161 cases of mitral valve prolapsed with sudden cardiac death or cardiac arrest. Female preponderance was seen in this study as $69 \%$ of cases were female.
The Median age affected population was 30 years. The complications listed were Cardiac arrest in $47 \%$ in stressful situations due to ventricular Fibrillation in $81 \%$. Seventy percent of the cases had Bi-leaflet involvement with Redundancy (99\%) and Non severe Mitral Regurgitation (83\%) [4].

Another study by Tolga Sinan Guvenc., et al. (2010) indicated that the prevalence of MVP was significantly higher in people living at moderate altitude than those living at sea level [5].

A population-based study by Sudhakar Sattur., et al. (2010) reports an overall prevalence of mitral valve prolapse at $0.7 \%$ with significantly higher among female teenagers complicated with Mitral and tricuspid valve regurgitation in teenagers with Mitral valve Prolapse [6].

Another population based study by Lisa A. freed., et al. (1999) reported that none of the subjects with prolapsed had a history of heart failure, one $(1.2 \%)$ had atrial fibrillation, one $(1.2 \%)$ had Cerebrovascular disease and three (3.6\%) had syncope, as compared with unadjusted prevalence of these findings in the subjects without prolapse of $0.7,1.7,1.5$ and $3 \%$ respectively [7].

\section{Conclusion}

We report a case of an young lady with symptoms of palpitations, chest discomfort, fatigue, dizziness, shortness of breath and anxiety being diagnosed as Mild mitral valve prolapse (MVP) with the help of 2D echo cardiogram. Medical treatment gave quick relief in 3 days. She was advised to report if any symptom persists. Other advice included living stress free life with physical exercises, yoga, and Meditation.

\section{Take Home Messages}

- MVP needs regular health check-ups and consulting physician once in a year.

- $\quad$ Reassurance and counselling for a stress-free life.

- $\quad$ Prevention of endocarditis and Valve surgery if needed.

\section{Bibliography}

1. "Valvular Heart Diseases".

2. R Gupta., et al. "Mitral valve prolapse: two dimensional echocardiography reveals a high prevalence in three to twelve year old children". Indian Pediatrics 29.4 (1992): 415-423. 
3. Liu PY., et al. "Prevalence and characteristics of mitral valve prolapse in military young adults in Taiwan of the CHIEF Heart Study". Scientific Report 11.1 (2021): 1-10.

4. Han HC., et al. "Mitral valve prolapse and sudden cardiac death: A systematic review". Journal of the American Heart Association 7.23 (2018).

5. Güvenç TS., et al. "Prevalence of mitral valve prolapse in residents living at moderately high altitude". Wilderness and Environmental Medicine 23.4 (2012): 300-306.

6. Sattur S., et al. "Prevalence of mitral valve prolapse and associated valvular regurgitations in healthy teenagers undergoing screening echocardiography". Experimental and Clinical Cardiology 15.1 (2010): 19-21.

7. "Mitral-Valve Prolapse".

\section{Assets from publication with us}

- Prompt Acknowledgement after receiving the article

- Thorough Double blinded peer review

- Rapid Publication

- Issue of Publication Certificate

- High visibility of your Published work

Website: www.actascientific.com/

Submit Article: www.actascientific.com/submission.php

Email us: editor@actascientific.com

Contact us: +919182824667 